\title{
LAS TEORÍAS DE LA MODERNIDAD REFLEXIVA Y DE LOS SISTEMAS SOCIALES: APORTES A LA COMPRENSIÓN DE LAS MACROTENDENCIAS DE LA EDUCACIÓN CONTEMPORÁNEA
}

\author{
Flora Eugenia Salas Madriz \\ Docente de la Escuela de Administración Educativa \\ de la Universidad de Costa Rica \\ San José, Costa Rica
}

Recibido 03-X-2006

Aceptado 14-XI-2006
Las instituciones fracasan víctimas de su propio éxito.

Montesquieu
Resumen: En este artículo se describen y analizan algunos aportes de los sociólogos Anthony Giddens, Scott Lash, Ulrich Beck y Elizabeth Gernsheim, para la comprensión de los cambios que ha sufrido la sociedad en general y la familia en particular, con el paso de la Edad Media a la Era Moderna y a la Posmodernidad. Estos pensadores son representantes de la teoría sociológica conocida como "Teoría de la Modernidad Reflexiva", a partir de la cual revisan $y$ explican algunas de las funciones tradicionales $y$ emergentes de la familia, como entidad social paradigmática. Con base en algunas de sus conclusiones se examinan nuevas demandas educativas de la sociedad, con el propósito de revisar cometidos para la educación en ese contexto. Se revisan algunas tesis de Luhmann sobre el origen moderno de la educación y el déficit tecnológico en pedagogía, para señalar algunas de las macrotendencias de la educación contemporánea en el contexto de la modernización.

Palabras clave: Modernidad, posmodernidad, modernidad reflexiva, sistemas sociales, cambio social y educación, funciones sociales de la familia, funciones sociales de la educación, cambio de época, cambio en las demandas educativas en la sociedad posmoderna.

\section{Introducción}

Las últimas tres décadas del siglo $\mathrm{XX}$ tuvieron un gran significado para las ciencias sociales, pues en ellas se manifestaron fenómenos sociológicos inéditos en Occidente que pusieron en evidencia una recomposición de la familia, de la estructura económica y, en general, de la sociedad tradicional heredada del medioevo y la industrialización. En la rearticulación de lo social de los últimos treinta años, situaciones como el incremento acelerado de la tasa de divorcios, de personas viviendo solas, de nuevos arreglos de pareja sin mediación del matrimonio, del incremento de familias con madres como jefas del hogar, de niños y niñas con dos o tres hogares, y de hijos adoptivos o nacidos a través de la ingeniería genética hicieron surgir muchas dudas, debido a que las fórmulas teóricas conocidas para comprender la familia y sus funciones perdieron su capacidad explicativa, lo que hizo necesario una revisión de 


\begin{abstract}
This paper describes and analyzes some contributions from sociologists Anthony Giddens, Scott Lash, Ulrich Beck and Elizabeth Gernsheim, for the comprehension of the changes faced by society in general and the family in particular, with the transition of the Middle Age to the Modern Age and Post modernity. These thinkers represent the sociological theory known as the "Reflexive Modernization Theory", from which they review and explain some of the traditional and emergent family functions, as a paradigmatic social entity. Based on some of their conclusions, new educational social demands are examined, with the purpose of reviewing educational tasks in this context. Some Luhmann theses about the origin of modern education and pedagogical technological deficit are reviewed, in order to point out some of the macro trends of contemporary education in the context of modernization.
\end{abstract}

Key words: Modernity, post modernity, reflexive modernization, social systems, social change and education, family social functions, education social functions, age transition, changes in educational demands in post-modern society. la teoría de la modernización simple y dar paso a enfoques teóricos que dieran cuenta de la complejidad social propia de la modernización y de su impacto en la familia.

En un escenario de desconcierto y cambio social acelerado, la teoría de la modernización reflexiva surgió como alternativa ante la creciente confusión del sistema social postindustrial, adicionalmente complejizado por la nueva estructura económica del capitalismo tardío, las tecnologías de la información y la comunicación (TIC), y la nueva fase política desencadenada por la globalización. En el nuevo enfoque, modernización reflexiva “... significa la posibilidad de una (auto)destrucción creativa de toda una época: la de la sociedad industrial [...] El sujeto de esta destrucción creativa no es la revolución, ni la crisis, sino la victoria de la modernización occidental" (Beck, Giddens, \& Lash, 2001, p. 14). Según estos autores, tal "autodestrucción creativa" de la época moderna se debe explicar desde sus orígenes en la fase industrial, a partir de sus propias lógicas y dinámicas, para lo cual, dadas sus funciones sociales primarias, proponen a la familia nuclear como elemento clave a estudiar, a fin de crear un marco explicativo de los cambios más significativos registrados hasta hoy en relación con sus características, configuración y funciones, como se verá a continuación.

En ese contexto, la educación al igual que todas las instituciones nacidas en la Modernidad enfrenta el reto de ajustar sus funciones y prácticas a las demandas sociales de nuestro tiempo. La comprensión de los profundos cambios y transformaciones de la familia y el sujeto es un factor clave para el giro educativo que está en ciernes. Los aportes de la sociología son un insumo de gran valor para el desarrollo de la teoría educativa en la fase de modernización de la modernización que llamamos Posmodernidad. Por eso se analizan los supuestos de la teoría de la Modernidad Reflexiva y se aplican algunos de sus hallazgos para interpretar macrotendencias de nuestro tiempo en el ámbito de la educación. 


\section{Supuestos de la teoría de la modernización reflexiva}

La paradoja de la Modernidad es que sus logros políticos, económicos y sociales hoy se revierten contra ella. La simbiosis histórica entre capitalismo y democracia ha acumulado suficientes tensiones como para poner en evidencia el agotamiento de los modelos clásicos, pero no por ello se han extinguido las tesis básicas de la democracia y de la libertad como fundamento de la vida económica y social. Las instituciones clave de la modernidad: la racionalidad instrumental que dio paso al desarrollo científico y la industrialización, el Estado nacional y las organizaciones públicas y privadas como base del control reglado de las relaciones sociales, se han "desbocado" por la velocidad del cambio social que rebasa la capacidad de estas entidades para redefinir sus metas y controlar las variables del impacto de esos cambios en sus prácticas sociales y en sus modos de comportamiento establecidos.

¿Qué significa este "quiebre" de las formas sociales tradicionales de la fase industrial y la incapacidad de sus instituciones fundamentales para responder a las nuevas características y demandas de la sociedad? Beck, Giddens y Lash (2001), proponen que este agotamiento de la fase industrial no es más que el resultado de sus propios logros en tanto modernización de la modernización, y que las formas sociales industriales están dando paso a otro tipo de "modernidad", que estos autores llaman modernidad reflexiva:

... en virtud de su dinamismo inherente, la sociedad moderna está minando sus formaciones de clases, estratos, ocupaciones, roles de género, familia nuclear, fábricas, sectores empresariales y, por supuesto, también los prerrequisitos y formas continuadas de progreso tecnoeconómico natural. Esta nueva etapa, en la que el progreso puede convertirse en autodestrucción, en la que un tipo de modernización socava y transforma otro, es lo que yo denomino fase de modernización reflexiva. (Beck, Giddens y Lash, 2001, p. 15)
Contrario a la tesis marxista de que el capitalismo se autodestruiría como consecuencia inevitable de las crisis que provocan sus contradicciones inherentes, para estos autores lo que produce esta destrucción desde "adentro", no son la crisis ni la revolución, sino, paradójicamente, las victorias del capitalismo. Los logros políticos, científicos, económicos, sociales e individuales de la Modernidad hoy presionan de manera no deseada y no prevista, por un orden social completamente otro, en el que se “... quiebran las premisas y contornos de la sociedad industrial y se abren vías a una modernidad distinta". (ibídem)

Un ejemplo de las transformaciones del paso de la Modernidad en su fase industrial a la postindustrial está relacionado con las mujeres. A lo largo del siglo XX hasta hoy, en Occidente se favorece la participación de la mujer en la vida política, social, científica y económica, pero ello ha incidido en cambios profundos en la estructura familiar tradicional y en los roles establecidos desde entonces para las mujeres. El desencadenamiento de eventos no provistos y no deseados vinculados al incremento en los derechos de las mujeres, en cuanto a sus funciones en la trama social tradicional provocaron una quiebra en las premisas de la familia, las relaciones de pareja, la maternidad, el trabajo femenino y los derechos y deseos de las mujeres.

Frente a sus logros y paradojas, la modernización de la modernización desencadena acontecimientos que van más allá de cualquier previsión que pudo hacerse hace cien años. Muchas de las consecuencias de la lógica moderna son y siguen siendo contradictorias a sus premisas originales:

Al mismo tiempo, la modernización reflexiva abarca un único dinamismo de desarrollo, que por sí mismo, aunque en contextos diferentes, puede tener consecuencias opuestas. En varios grupos culturales y en continentes diversos va acompañada de nacionalismos, pobreza masiva, fundamentalismo religioso de facciones y fes diversas, crisis económicas, crisis ecológicas, posiblemente guerras y revoluciones, sin 
olvidar los estados de emergencia provocados por grandes accidentes catastróficos; es decir, el dinamismo conflictivo de la sociedad del riesgo en el sentido más estricto. (Beck, Giddens y Lash, 2001, p. 17)

Si bien las mujeres han logrado derechos y oportunidades que les fueron negadas durante milenios, también hoy son las ciudadanas más pobres del mundo y muchas pagan su derecho a ser felices con la muerte, asesinadas por sus compañeros o esposos y, en el mejor de los casos, con la soledad. En la nueva sociedad del riesgo:

\footnotetext{
...los conflictos sobre la distribución de los "males" se superponen a los conflictos sobre la distribución de los "bienes" (renta, trabajo, seguridad social) que constituyeron el conflicto básico de la sociedad industrial y se intentaron solucionar en las instituciones relevantes. Estos conflictos sobre la distribución de males pueden interpretarse como conflictos sobre la responsabilidad distributiva. Surgen en torno a la distribución, prevención, control y legitimación de los riesgos que acompañan a la producción de bienes (megatecnología nuclear y química, investigación genética, amenazas ambientales y supermilitarización y creciente depauperización fuera de la sociedad industrial occidental. (Beck, Giddens y Lash, 2001, p. 19)
}

Si bien las consecuencias y cambios provocados por la Modernidad en su fase industrial en la trama social, política, institucional, científica y económica son evidentes, no ha sido así con los que provocó en otras dimensiones, en particular en la vida individual y en la constitución del yo, porque:

...la modernidad altera de manera radical la naturaleza de la vida social cotidiana y afecta a los aspectos más personales de nuestra experiencia. La modernidad se ha de entender en un plano institucional; pero los cambios provocados por las instituciones modernas se entretejen directamente con la vida individual y, por tanto, con el yo. Uno de los rasgos distintivos de la modernidad es, de hecho, una creciente interconexión entre los dos "extremos" de la extensionalidad y la intencionalidad: las influencias universalizadotas, por un lado, y las disposiciones personales, por otro. (Giddens, 1998, p. 9)

En este entorno, las tendencias evolutivas de la sociedad deben comprenderse, a fin de ofrecer marcos de referencia que orientan la toma de decisiones en instituciones clave de la era postradicional. Entre ellas, la educación ha cobrado ese nivel no sólo por la interconexión entre el sistema económico y el nivel educativo de la población, sino también por las necesidades de formación que hoy presionan por transformaciones profundas en los sistemas educativos en todas las regiones y países del mundo.

La teoría de la modernización reflexiva parte de tres supuestos fundamentales: la sociedad del riesgo, la individualización como forma social, la reflexión y la reflexividad. Por sociedad del riesgo se entiende una fase de desarrollo de la sociedad moderna en la que "... los riesgos sociales, políticos, económicos e individuales tienden cada vez más a escapar a las instituciones de control y protección de la sociedad industrial" (Beck, Giddens, \& Lash, 2001, p. 18). Este supuesto es consecuencia de una incapacidad creciente del marco institucionalizado de organización social actual para satisfacer demandas sociales tradicionales en los contextos emergentes, y para contener comportamientos individuales y sociales destructivos no previstos.

La indivualización como forma social implica la “... desintegración de las certezas de la sociedad industrial y la compulsión de encontrar y buscar nuevas certezas para uno mismo y para quienes carecen de ellas" (Beck, Giddens, \& Lash, 2001, p. 29). Como consecuencia de los logros de la modernidad en cuanto a libertades y derechos individuales se incrementó paulatina pero inexorablemente el ámbito de indefensión, soledad y angustia existencial, por lo que las personas se ven obligadas a enfrentar y resolver por sí mismas problemas que antes no existían gracias a la religiosidad y a la tesis de un libre albedrío regulado por códigos sabidos de conducta. Ser feliz no era una tarea personal, sino la resultante de aceptar el propio destino y de actuar con base en prácticas reconocidas como "buenas". De lo contrario, se esperaba el consabido horror del infierno. El camino a 
la felicidad y a la desgracia estaban "trazados" y, por ello, aún en el peor de los casos había consuelo y certidumbre.

La reflexividad se define como “... la transición autónoma, no deseada y no percibida desde la sociedad industrial a la sociedad del riesgo [mientras que] la reflexión es autoconfrontación" (Beck, Giddens, \& Lash, 2001, p. 18). La "conciencia de sí" marca la modernidad como derivación del reconocimiento de la individualidad y del derecho a elegir, pero ello tuvo consecuencias personales y sociales no previstas sobre las cuales aún hoy no tenemos la suficiente claridad y, por ende, tampoco respuestas. La necesidad creciente de explorar el deseo y el placer es una de las resultantes más complicadas de nuestro tiempo, tanto en el nivel individual como social.

Con base en los supuestos de la modernidad reflexiva los cambios que está sufriendo la sociedad actual, así como sus distintas manifestaciones en los arreglos diversos de la familia, la economía, la política y la cultura, son procesos propios de la modernización en su fase tardía que han dejado atrás estructuras obsoletas, consecuencia de efectos colaterales latentes no previstos de este proceso; es decir, dada su "imprevisibilidad", según la teoría de la Modernidad Reflexiva, estos cambios y transformaciones no pueden ser evitados ni revertidos, pese a que sus consecuencias sean indeseables y a que todavía no encontremos repuestas o alternativas.

La individualización como forma social propició una redistribución del poder en la sociedad actual que otorgó un nivel de poder personal único en la historia de Occidente; pero, a su vez, esto conlleva a que invariablemente las personas experimenten junto con su libertad, una mayor incertidumbre respecto de sí mismas, de su intimidad y de su futuro. Libertad e incertidumbre resultan articuladas en la modernidad reflexiva.

Como derivación irrevocable de la modernidad reflexiva y de la individualización como forma social, emerge la reflexión como medio para reinventar el curso de la historia personal y colectiva, y orientarlas hacia formas más coherentes y exitosas de vida en las que vuelvan a ser armónicas las relaciones, a pesar de los conflictos inherentes a la individualización, la sociedad del riesgo y la inevitabilidad del cambio y sus efectos colaterales latentes no deseados.

\section{La familia nuclear como objeto de estudio privilegiado de la teoría de la modernización reflexiva}

Ulrich Beck, Elisabeth BeckGernsheim y Anthony Giddens abordan la problemática de la familia en el contexto de la modernidad reflexiva. Para ello, exploran las posibilidades del amor de pareja en la era de la individualización y, en consecuencia, del amor como fundamento de expectativas individuales, cuya satisfacción queda determinada por el deseo, interés e intereses de otro. A su parecer, el amor en general es una experiencia fundamentalmente social que entra en contradicción con las fuertes tendencias hacia el individualismo de nuestro tiempo, pues las derivaciones de la confrontación yo-otro son la negociación, el respeto y la tolerancia, por un lado, y el conflicto, la soledad y la infelicidad, por otro. En la relación amorosa es fundamental ceder, reconocer y atender las necesidades de otra persona, interesarse por su bienestar, solidaridad, lealtad y fidelidad; pero ello supone que haya reciprocidad. De lo contrario no es viable, no prospera, no subsiste.

Si bien el arreglo amoroso de la pareja se vuelve romántico hasta muy recientemente, a finales del siglo XVIII (Beck \& Beck-Gernsheim, 2001; Giddens, 1998), se ha vuelto una necesidad creciente, compulsiva e impostergable de cada ciudadano del mundo Occidental encontrar una pareja por medio de la cual sentirse amado, protegido e importante para "un 
otro". Con el rompimiento de la estructura de la familia extendida tradicional y de las redes de apoyo que se articulaban en torno a ella, en términos de valores y mandatos sociales, el espacio de seguridad afectiva, sexual y material de la familia en nuestros días se restringe a la relación de la pareja, que puede o no tener o desear hijos, sin que por ello varíe la necesidad intrínsecamente humana de seguridad y amor.

Estudios médicos y psicológicos muestran que la carencia de amor lesiona profundamente nuestra salud psíquica $\mathrm{y}$ física, y también daña de manera inexorable nuestra posibilidad de convivir en armonía. La violencia social creciente que experimentamos en la sociedad occidental tiene que ver, según estos autores, con la dificultad para amar y ser amados que sentimos en la era de la individualización, la reflexividad y la reflexión. Por esta razón, el amor como experiencia crucial de la vida humana y la familia como contexto de "seguridad existencial" son temas de análisis obligatorio para la teoría de la modernidad reflexiva.

¿Cómo amar y ser amado en la era de la modernidad reflexiva, individualista y autocrítica? ¿Está condenada a muerte la familia como forma social o sólo se termina el modelo de familia "tradicional" que heredamos de la Edad Media? ¿Cómo afecta este contexto la práctica educativa y qué papel debe jugar la educación en la sociedad postradicionalista? Responder a estas preguntas no es fácil; sin embargo, los autores que se exponen a continuación ofrecen herramientas teórico-conceptuales para hacer un abordaje coherente del problema y, por consiguiente, algunas de sus conclusiones y hallazgos facilitan extrapolaciones del campo de la sociología al campo de la educación.

\section{La fragilidad y el significado de la familia en la modernidad reflexiva}

Beck y Beck-Gernsheim en su libro publicado en 1990 El normal caos del amor hacen un interesante análisis de las relaciones de pareja en Alemania para, con ese pretexto, hacer un abordaje histórico y sociológico de la evolución de la familia en Occidente, desde el feudalismo hasta el período actual. La relevancia de este trabajo es que explica con base en la teoría de la Modernidad Reflexiva la aparición de los conflictos en las relaciones amorosas, a partir de un recorrido desde la familia tradicional -base de la sociedad feudal, definida como "familia única para toda la vida"hasta la contemporánea, que se caracteriza por la posibilidad de ruptura de la unión de pareja en cualquier momento, si así lo consideran las personas involucradas.

A criterio de los autores, para el caso de Occidente la institución del matrimonio convive en nuestros días con el divorcio aceptado socialmente y protegido como un derecho a través de la institución jurídica. En esta evolución del arreglo familiar se pasó del "matrimonio de por vida" al "matrimonio por mutuo acuerdo", donde ambas partes tienen la opción de separarse si así lo desean. Este cambio no es trivial, sino que tiene profundas consecuencias sociales y psicológicas.

A lo largo del siglo XX, fueron abriéndose otras posibilidades para unirse en pareja. Hoy existen múltiples opciones de convivencia "no familiares", si tomamos como modelo la definición tradicional de familia. Para Beck y Beck-Gernsheim, esto no necesariamente significa la superación radical de un modelo de arreglo familiar por otro, sino que en nuestra época coexisten diferentes posibilidades de unión de pareja y configuración familiar que abren un amplio margen de opciones a los individuos, con toda la complejidad que ello implica en los niveles social, legal y cultural.

El amor de pareja es para estos autores un logro específico de la Modernidad, donde los distintos actores sociales alcanzaron un protagonismo único en la historia de la civilización occidental, que hizo posible una mayor individualización y democratización, por lo que se volvieron cruciales el 
diálogo, el consenso y la comunicación. En esa época, a diferencia de las anteriores, las personas dejaron de unirse en pareja exclusivamente para formar una familia y sobrevivir cumpliendo con los roles establecidos, como ocurría en la Edad Media. Se unen para intentar ser felices, sea lo que eso signifique para cada uno, y para tener la experiencia de amar y ser amadas. Apuntan como hecho decisivo para este cambio la incorporación creciente de la mujer al mundo del trabajo y, por ende, su autonomía económica, porque esto ha tenido un profundo impacto en la ordenación de la nueva familia en la Modernidad y la Posmodernidad. En este proceso, más allá de la autonomía económica, la mujer logró independencia como individuo; es decir, alcanzó el status de "persona" y de "ciudadana" que le ha hecho acreedora -al menos en teoría-, de igualdad de derechos y deberes respecto de los hombres.

El cambio de papel de la mujer en la pareja, consecuencia de la alteración de roles que propiciaron la sociedad capitalista industrial y postindustrial en la economía y la cultura, y de la evolución jurídica del estado de derecho tuvo inconcebibles consecuencias en las relaciones de poder heredadas de la época estamental. Los hombres son los grandes perdedores ante esos cambios, porque las nuevas posibilidades de las mujeres en lo que a autonomía económica y jurídica se refiere limitan y revierten en forma acelerada privilegios derivados de milenios de vigencia de la tradición patriarcal. De tener todos los derechos y libertades sexuales y patrimoniales, se han visto seriamente amenazados por las exigencias legítimas de las mujeres en cuanto a su gratificación sexual, afectiva, laboral y personal, y al derecho a la conquista y ejercicio del poder político y económico.

De la misma forma, el replanteamiento de la paternidad como un asunto que debe ser negociado con la madre y no supuesto como un derecho adquirido del esposo, hoy forma parte de la gran diferencia entre las expectativas de hombres y mujeres al entrar en una relación amorosa. Este conflicto entre los intereses de las mujeres y de los hombres frente a un imaginario colectivo que ha atravesado generaciones desde el feudalismo hasta hoy, es uno de los factores que tiene en crisis el modelo de familia tradicional.

Como complejidad adicional, con la libertad individual y los valores modernos el ser humano enfrenta la disyuntiva entre el amor "imaginario" y el amor "real", donde se entremezclan la fantasía y la verdad cotidiana del amor. La ambivalencia en la cual felicidad y rutina se enlazan, fractura la certeza y la aspiración del "amor para siempre". La trágica realidad de esta contradicción del amor en los tiempos modernos se refleja en la creciente tasa de divorcios y de personas que deciden vivir solas después de malas experiencias de pareja. La gente ya no está dispuesta a tolerar indefinidamente una relación en la que, por los motivos que sea, no se siente feliz, gratificada, realizada e interesada.

Las nuevas exigencias del mundo del trabajo introducen distractores y dificultades adicionales en la relación de pareja que reducen sustancialmente la cantidad y calidad de tiempo para compartir en la intimidad. Si la pareja tiene hijos su cuidado y atención requieren del concurso de ambos progenitores, debido a que los dos trabajan fuera del hogar. Esto puede ser fuente de conflicto si uno de los dos espera "comportamientos tradicionales en su pareja"; por ejemplo, si el hombre pretende que la mujer asuma la mayor parte de las tareas domésticas y él solo "ayuda"; o bien, si la mujer espera que el hombre no se involucre y sea sólo "el proveedor" que tradicionalmente se supone debe ser.

Si bien estos problemas parecen ser específicos de la pareja, ello pone en evidencia aspectos más transcendentales que tienen que ver con una transformación en la estructura social general. Al respecto, Beck y Beck-Gernsheim consideran que los principales factores del cambio estructural de nuestra sociedad son los siguientes: 
a. Los roles de género, donde cambia la relación de desigualdad entre hombres y mujeres que dio pie a la sociedad industrial, debido a que permitió procesos de mercantilización incompleta al no reconocer salarialmente el trabajo femenino.

b. La dinámica individualizadora, que ha permitido una liberalización creciente de las adjudicaciones tradicionales del género, por lo que hombres y mujeres se orientan a buscar una "vida propia", donde puedan tener márgenes lo suficientemente amplios para realizar sus deseos, expectativas y aspiraciones personales.

c. Por lo anterior, la familia sólo es un lugar más donde se expresan los conflictos de la convivencia y no su causa.

Los enfrentamientos privados de una serie de conflictos macrosociales han vuelto a la familia un lugar vulnerable a la crisis y al manejo de la crisis. En este sentido, el desencanto, la soledad y el desamor parecen acompañar la realidad, más allá del fantaseo de la felicidad amorosa que venden los medios de comunicación de masas. Paradójicamente, cuando mayor libertad hay para amar es cuando mayores obstáculos encuentra la persona para alcanzar sus expectativas como sujeto y objeto de amor. La tesis que plantean los autores es que existe un desfase fundamental entre los supuestos de la modernidad y su realidad; es decir, que “... la igualdad de hombres y mujeres no se puede conseguir en estructuras institucionales que presupongan la desigualdad de hombres y mujeres. No podemos meter a los nuevos seres humanos "redondos" en los viejos cajones "cuadrados" del mercado laboral, el sistema profesional, el urbanismo, el sistema de protección social, etc." (Beck \& Beck-Gernsheim, 2001, p. 51). Así las cosas, lo que se debe ajustar a la realidad son las estructuras sociales y no al contrario, como ingenuamente se pretende y espera.
La principal llamada de atención de Beck y Beck-Gernsheim es que vivimos en la actualidad con base en instituciones obsoletas y tratamos de encajar la realidad dentro de estructuras que ya no funcionan. Como consecuencia, el discurso y necesidades de la ciudadanía no son atendidos por los mecanismos sociales vigentes. Se ha focalizado de manera equivocada la problemática: no es la gente la que "repentinamente se volvió loca", sino que las instituciones y mecanismos sociales actuales ya no son afines con la realidad individual y colectiva del presente. Los viejos modelos de organización social no permiten la coherencia mínima necesaria entre prácticas sociales concretas y mecanismos de control institucionales. No es que no haya respuesta, es que se están ofreciendo las respuestas equivocadas.

Las contradicciones en la pareja introducidas por la nueva estructura laboral, económica, política, social y cultural, son resultado de la estructura dominante de valores obsoleta que deviene dominante por la tradición, pero ello no impide que sea permanentemente desafiada por las nuevas dinámicas valóricas del contexto actual. En este sentido la "destradicionalización" se vuelve una tendencia inevitable, cuyo propósito es ofrecer nuevas posibilidades de organización familiar y de pareja más coherentes con las necesidades personales y colectivas de hoy.

Entre más jóvenes son las personas, parece haber una mayor capacidad de adaptación a las estructuras emergentes. Sin embargo, existen generaciones atrapadas en una mayor ambigüedad entre la tradición y las tendencias propias de la modernidad reflexiva. Esta tensión hace que la biografía entre en crisis en el tanto ella no es una construcción abstracta, sino inscrita en la lógica de las instituciones sociales que la hacen posible; a decir de los autores, “... eso significa que las situaciones individuales dependientes de instituciones implican discriminaciones o ventajas generacionales, las así llamadas situaciones de cohortes, 
precisamente por cuestiones demográficas y coyunturas económicas o del mercado laboral". (Beck \& Beck-Gernsheim, 2001, p. 67)

Con base en la tesis de las cohortes se puede afirmar que estamos en una etapa de transición en la que aún son confusas las nuevas formas de organización social y prevalecen valores tradicionales, pero que ya no permiten la estabilidad ni el equilibrio a mediano y largo plazos. Desde este punto de vista, consideran los autores que esta ambigüedad se evidencia en el ensayo de formas y arreglos de la intimidad prescritos y de instituciones que tratan de administrar desde lo político la época industrial en fase de extinción. (Beck \& Beck-Gernsheim, 2001)

Ahora bien, esta ambigüedad propia de la fase de transición tiene una consecuencia específica en la relación de pareja, ya que “... cuantos más referentes se pierden para la estabilidad [social y personal], más dirigimos hacia la relación con la pareja la necesidad que sentimos de dar sentido y arraigo a nuestra vida" (Beck \& Beck-Gernsheim, 2001). Así las cosas, sostienen los autores que la familia y la pareja en particular han recibido una sobrecarga de las expectativas sociales que se vuelcan al plano de la intimidad. La gran batalla del cambio social se vive en el campo íntimo de la persona y en la familia como su referente inmediato. Los conflictos entre generaciones o cohortes se vivencia como conflicto entre padres e hijos. La ambigüedad entre individualismo y colectividad se presentifica en las contradicciones más íntimas de la pareja, particularmente en el ámbito de la sexualidad.

El éxito laboral y económico queda comprometido en procesos de solidaridad, comprensión y apoyo de la familia. Cada logro personal se convierte en "sacrificar a la familia". Sin ese soporte, difícilmente se alcanza el desarrollo personal y muchas parejas no sobreviven a esta prueba. Además, el fracaso en la relación de pareja a edades tempranas obliga a las personas a replantear sus necesidades, expectativas e intereses, ya que después de la ruptura se ven ante el deseo y la necesidad de reiniciar relaciones de pareja y esto es aún más difícil de alcanzar si se tienen hijos propios, si la nueva pareja los tiene y, peor aún, si ambos los tienen.

Por otra parte, el carácter simbiótico de la pareja hace que la salida de este tipo de relación implique una crisis biográfica que marca para el resto de la vida. Por esta razón, algunas personas se quedan solas un tiempo, otras se relacionan íntimamente con personas que compartan su realidad $\mathrm{y}$, por ende, que puedan entenderla. Por ejemplo, si tienen hijos quizá alguien que también los tenga pueda tolerar con mayor facilidad las implicaciones de la maternidad y la paternidad en la vida cotidiana. O bien, ensayan relaciones esporádicas, sin comprometerse demasiado, para no caer en el riesgo de depositar de nuevo algo fundamental de sí mismas en la existencia y presencia de un "otro". Hoy es común encontrar personas que viven con sus parejas y que tuvieron previamente otras relaciones e, inclusive, tienen hijos, tanto de las relaciones pasadas como de la actual, lo que dificulta aún más los vínculos.

En una línea continua que va desde el matrimonio tradicional hasta la unión libre, quedando entre ellas múltiples posibilidades, la relación de pareja es la más vulnerable de las formas sociales contemporáneas; pero también, según los autores, es el lugar donde se gesta la sociedad del futuro. Desde los ensayos de pareja y de familia prescritos hasta la ingeniería genética, se rebasan ampliamente los esquemas tradicionales de valores de nuestra sociedad heredados de la Edad Media y fuertemente anclados en la moral cristiana y en la inequidad en la distribución del poder económico, social y personal. El amor como esta salida de la religión, es decir, como posreligión se dirige a la instauración de una sociedad más democrática, donde las cosas probablemente no serán perfectas, pero en la que los seres humanos tendrán más posibilidades de ser ellos 
mismos y de encontrar un sentido personal a su existencia:

El fundamento del amor es siempre y únicamente el amor mismo. Argumentando operacionalmente, eso significa que sólo los amantes pueden juzgar si aman. El amor es democracia radical a dos, es el prototipo de la autorresponsabilidad. Lo es hasta tal extremo que incluso comprende la irresponsabilidad, porque únicamente los amantes -y de ello se deduce que también uno en contra del otro- pueden comprobar y ejecutar para los dos el final del amor, sin otro argumento que el amor, su amor, el amor de él o de ella, se ha apagado. (Beck \& Beck-Gernsheim, 2001, p. 264)

\section{El origen de la educación como institución moderna}

En la sociedad occidental premoderna la marca de la explicación del mundo a partir de la creación divina dejó su huella indeleble. La tesis de fondo de esta explicación es que el estado imperfecto del mundo, entendido como "mundo humano", al tener un origen divino podía y debía tender a la perfección. Esta ambigüedad original de la naturaleza humana hizo posible a lo largo de la Edad Media un universo semántico de diferencias marcadas por una lógica binaria: naturaleza/divinidad, perfección/imperfección, nobleza/no nobleza, belleza/fealdad, $\mathrm{y}$ bien/mal, por mencionar algunas.

La teoría de la educación de Luhmann (1996) se inicia con la revisión de las teorías creacionista y de la emanación que entraron en crisis a partir del siglo XVIII, debido a la creciente deslegitimación de sus fundamentos al entrar en la Modernidad. El nuevo orden social burgués, sin embargo, no pudo liberarse de la tradición que le antecedió, por lo que en esta época se siguieron utilizando vías tradicionales para explicar y organizar las formas sociales emergentes que trajo consigo. La educación fue uno de los elementos que surgió con funciones y características radicalmente distintas en ese período, pese a que se fundó y estructuró en relación con las tesis propias de la Edad Media. La razón se consideró como "la naturaleza" del ser humano y la sociedad continuó tematizándose desde la moral.

Pese a que la educación surgió en un escenario de fundamentación moral, idealista y normativo, problemas como: ¿cuándo iniciar la enseñanza formal y cuando terminarla?, ¿cómo enseñar y cómo saber si los alumnos aprenden?, o ¿quiénes deben ser educados? hicieron su aparición en el universo educativo. Esto trajo consigo el desarrollo de puntos de vista profesionales para el proceso educativo, por lo que el problema del método de enseñanza adquirió importancia.

El orden social "civilizado" visto como "naturaleza" en la incipiente Modernidad exigió la creación de un sistema para transformar a las personas del "estado natural" a un "estado civilizado", y esta fue una de las principales funciones de la escuela moderna en sus comienzos. El "estado de civilización" fue sinónimo de "progreso", entendido como la posibilidad de una cada vez mejor condición humana para explotar la naturaleza y sus diferencias. Pero, el sistema educativo también tenía otra posibilidad: la estratificación social en términos del talento y la capacidad de las personas.

Luhmann (1996) considera que la noción de progreso y la estratificación social propias de la educación moderna marcaron el vínculo de los sistemas educativo y económico, ya que la economía capitalista se vio forzada a adquirir del sistema educativo y no de la naturaleza las capacidades humanas necesarias para el trabajo industrial. Debido a este vínculo la educación y la economía se rigen, tanto en el nivel cuantitativo como cualitativo, por la lógica económica propiamente dicha. Esta vinculación fortaleció la insuficiencia de los modelos educativos de fundamentación moral, idealista y normativa. El déficit teórico y, en consecuencia, tecnológico de la educación y la pedagogía se hace cada vez más evidente con el desarrollo del sistema económico capitalista, cuyos presupuestos son el incremento de la productividad a través del desarrollo científico y la aplicación 
de estos conocimientos en los procesos de producción y distribución de bienes y servicios. La tecnología, base técnica del modo de producción capitalista, se convirtió en la columna vertebral de la sociedad moderna (Marx, 1974, 1980), lo que hizo dependiente a este sistema de la creación del conocimiento científico.

Los problemas educativos se redujeron a problemas de método a partir de la segunda mitad del siglo XVIII. Secuenciación, inicio y gradación de la educación, observación del profesor de la actividad de los alumnos, coordinación entre profesores $y$ alumnos, entre otros problemas, fueron objeto de análisis de la pedagogía para dar respuesta a las demandas educativas emergentes de la sociedad industrial. La respuesta a estas interrogantes se dio en el marco del pensamiento tradicional premoderno: en la enseñanza se debía partir de lo simple para avanzar hacia lo complejo, y ello marcó el desarrollo ulterior de las organizaciones educativas y del currículum como factores clave de la modernidad (Luhmann, 1996).

La necesidad creciente del sistema económico de fuerza de trabajo con grados diversos de enseñanza, exigió al sistema educativo mecanismos de homogeneización que garantizaran unos mínimos de educación. Pero, también la diversificación de las demandas educativas de la industrialización trajo consigo la necesidad de diferenciación al interior del sistema, por lo que los programas y la gradación se convirtieron en una alternativa para responder a necesidades educativas opuestas: homogeneización y especialización.

Con la homogeneización y la especialización de la educación, las viejas formas de fundamentación de la pedagogía entraron en crisis. El thelos tradicional de la educación fue reemplazado por las derivaciones funcionales del sistema educativo. Ante la realidad social sólo queda la comparación de rendimientos educativos, por ejemplo: hay estudiantes mejores que otros, unos que finalizan los programas y otros que no, unos desertan y otros no. Esta nueva concepción estructural y semántica de la educación moderna corresponde, a criterio de Luhmann, a la inserción de límites temporales que marcan el principio y el fin del proceso educativo, de la "responsabilidad del sistema sobre sí mismo" (Luhmann, 1996, p. 53) y del sujeto como actor responsable de los resultados educativos.

El sistema educativo difiere responsabilidades, para derivar autonomía relativa a sus actores; es decir, universaliza, por un lado, y personaliza, por otro. Esto es coherente con la tesis de Giddens, de que uno de los rasgos distintivos de la modernidad y sus instituciones es "... una creciente interconexión entre dos extremos de la extensionalidad y la intencionalidad: las influencias universalizadoras, por un lado, y las disposiciones personales, por otro". (Giddens, 1998, p. 9)

Conforme el capitalismo industrial se hace más complejo la capacidad de previsión del sistema en general y en educación en particular se ve reducida. Esto ocurre porque, según la teoría de los sistemas sociales, toda reducción de complejidad implica un aumento de complejidad no conocida, determinado en cada nivel por la formación de sistemas y su relación con el entorno (Luhmann, 1998). Esto se debe a que los sistemas sociales no acumulan indefinidamente la complejidad sino que, bajo ciertas condiciones, esa acumulación de complejidad produce una interrupción y un nuevo comienzo de construcción de complejidad. Esto explica por qué la modernización de la modernización, según la teoría de la Modernidad Reflexiva, conlleva un quiebre en las premisas y contornos de la sociedad industrial que abre vías a una forma de sociedad distinta, y que produce eventos sociales no previstos y no deseados. Uniendo el enfoque de Luhmann con los aportes de la teoría de la Modernidad Reflexiva, "la sociedad moderna que se moderniza" entra en un nuevo comienzo de construcción de complejidad, donde las instituciones clave se enfrentan a transformaciones funcionales. 
Para Luhmann (1998) la sociedad es un orden siempre emergente en el sentido que no puede verse afectada por nada que esté fuera de ella pero, debido a la peculiaridad de los sistemas abiertos, autocontenidos y autopoiéticos, precisamente por ser un orden siempre emergente configura "un mundo que no coincide punto por punto con las condiciones de posibilidad sobre las que se sustenta y de donde ha surgido" (Luhmann, 2000, p. XIX). Los sistemas abiertos desarrollan complejidad para crear neguentropía ${ }^{1}$, para lo cual deben intercambiar energía o información con el entorno y estos intercambios les permiten conservarse. El sistema social es un compendio de sistemas que al conservarse contribuyen a la conservación del sistema social como un todo. Pero también estos intercambios introducen elementos nuevos al sistema que pueden producir efectos no previstos.

A partir de la Modernidad la educación se convirtió en una institución indispensable para la producción y reproducción de la sociedad capitalista emergente. Con el desarrollo del capitalismo el sistema educativo ha evolucionado cuantitativa $\mathrm{y}$ cualitativamente, y hoy está compuesto por organizaciones graduadas cuya función es, al menos en principio, el cambio de las personas. Siguiendo la tesis de Luhmann de que la Pedagogía posee un déficit tecnológico que hereda desde sus orígenes modernos «cuyas bases fueron la filosofía kantiana, el idealismo alemán y la antropología filosófica neohumanista", desde entonces se fundamenta en idealizaciones, moralizaciones o atribuciones de fracaso, y por ello los procesos de decisión en este campo se despliegan sobre premisas arbitrarias que refuerzan dicha fundamentación.

El verdadero problema a resolver en la actualidad es esclarecer si es posible aún la pedagogía si no es dable su fundamentación científica y no cómo se pueden controlar mejor los efectos de la educación o si habría que hacerlo. Siguiendo esta tesis de Luhmann, la cuestión decisiva para la educación contemporánea es comprender qué consecuencias teóricas y prácticas se derivan de que la situación educativa permanezca en un estado de déficit tecnológico, en un contexto donde las demandas sociales por educación se incrementan y diversifican. Lo que se debe esclarecer, entonces, es cuáles son las derivaciones funcionales del sistema educativo en el contexto de la sociedad posmoderna y postradicional.

\section{Macrotendencias de la educación en la posmodernidad: funciones y desafíos}

Compete a la educación, en tanto institución encargada del proceso de socialización secundaria, asumir el reto de comprender el contexto y la coyuntura social actuales, para que se convierta en una institución que contribuya a la conformación del nuevo orden social que está en ciernes. De lo contrario, sólo será un obstáculo para ello, al tratar de preservar, produciendo y reproduciendo un orden social que está en vías de extinción.

Como institución social la educación, al igual que las demás instituciones que han servido para estructurar la civilización occidental en la fase industrial, está en crisis. Hace aproximadamente veinticinco años que se habla de crisis en educación, y apenas se empiezan a ensayar opciones educativas más coherentes con las nuevas demandas, intereses y características de nuestra sociedad. Mientras tanto, la deserción creciente, la baja promoción, la pérdida de relevancia de la educación formal pública, la inequidad y la baja calidad educativa siguen siendo evidentes en las nuevas generaciones.

Los conflictos inherentes a la individualización, la sociedad del riesgo y el cambio acelerado y sus efectos colaterales latentes hace tiempo ingresaron a las aulas. La violencia doméstica, la descomposición de la familia tradicional, la violencia 
sexual, la legitimación creciente en nuestra cultura de la violencia por la violencia, el abandono y abuso infantil, la diversidad de arreglos familiares, la presión del mundo del trabajo, el avance vertiginoso de las nuevas tecnologías de la información y la comunicación, el impacto de la globalización en los países y sectores sociales más pobres y vulnerables, las adicciones, la destrucción de la naturaleza a escala planetaria, los peligros inherentes al cambio climático y la creciente inequidad mundial en la distribución del ingreso, sólo para mencionar algunos de los problemas sociales más apremiantes, obligan a la educación a replantearse desde sus cimientos, en tanto institución clave en el nuevo contexto social. Prueba de ello son las preocupaciones y temáticas de los últimos foros $\mathrm{y}$ conferencias mundiales sobre educación, en particular, el Foro sobre la Educación de Dákar (UNESCO, 2000).

En la conferencia de Dákar se depositó una gran responsabilidad sobre la educación como institución específicamente moderna, nacida en la era industrial e indispensable para el futuro de nuestra civilización, pues se supone que sus fundamentos no pueden ser otros que principios democráticos y la producción y distribución equitativa del conocimiento, la ciencia y la tecnología. Desde esta perspectiva, la educación no sólo es clave para atenuar la pobreza, sino también para alcanzar los objetivos de la sociedad democrática (UNESCO, Informe Final Foro Mundial sobre la Educación, 2000). Pese a ello, para el 2000 se contabilizaban 119 estados democráticos en el mundo y en estos países vivía únicamente el $58 \%$ de la población global. La meta entonces fue elevar esas cifras hasta lograr que toda la humanidad goce de los beneficios y libertades de ese sistema político, superando finalmente las dictaduras, los totalitarismos y el autoritarismo.

Otro aspecto relevante es la mundialización económica y la expansión de la economía de mercado que ha introducido profundas disfunciones en el sector político, pues obliga a que en las decisiones estatales primen intereses y razones económicas y no la estabilidad, el bienestar y el orden social. $\mathrm{Al}$ respecto, se discutió en ese foro que la educación debe permitir una repolitización de la sociedad civil para contrarrestar las fuerzas ciegas del mercado. Es decir, la educación debe permitir el pensamiento crítico, reflexivo, creativo y socialmente responsable, que haga dable una reorientación de la economía globalizada y globalizante hacia formas menos autodestructivas e inequitativas en los niveles personal, social, económico, político y ecológico.

En nuestro tiempo es común que los estados "democráticos" resuelvan los problemas incrementando sus presupuestos para la construcción de cárceles y la contratación de policías, porque hace ya varias décadas se olvidaron de incluir en las cuentas nacionales la inversión en el control de la corrupción pública y privada, la salud, la educación, la vivienda y el desarrollo social sostenible -lamentablemente-, como bien sabemos los costarricenses, nuestro país no es la excepción.

Como otro elemento interesante, en el foro de Dákar se acordó suprimir las disparidades entre los géneros en la enseñanza primaria y secundaria para alcanzar antes del 2015 la igualdad entre los géneros en relación con la educación. Si esto se logra, se va a acelerar la incorporación de la mujer al trabajo y, por ende, a estimular la salida del modelo de familia tradicional al propiciar el cambio del rol social y económico en sectores femeninos aún marginados, particularmente en el Tercer Mundo. Las consecuencias de este cambio de roles de las mujeres en las regiones más atrasadas del planeta aún no se considera en las agendas y las políticas públicas.

Conscientes de las dificultades inherentes a la extinción de referentes sociales y culturales de la industrialización, especialmente los de la familia, en el foro se propuso como parte del marco de acción, “... crear un entorno educativo seguro, sano, integrado y dotado de recur- 
sos distribuidos de modo equitativo, a fin de favorecer un excelente aprendizaje y niveles bien definidos de rendimiento para todos" (UNESCO, Informe Final Foro Mundial sobre la Educación, 2000, p. 44). Desde el punto de vista de la teoría de la modernidad reflexiva, esto supone que la educación debe jugar un papel explícito en el proceso de administración de la fase industrial en extinción, al suplir espacios de estabilidad y certidumbre en un contexto donde imperan la inseguridad y la falta de equilibrio, especialmente para niños, niñas y jóvenes.

En cuanto a la individualización con responsabilidad social y personal, se ha tomado conciencia de que el paradigma educativo tradicional y el basado en la teoría del aprendizaje conductista masificado ya no responden a las demandas educativas del presente. Por esta razón, también se ha discutido en distintos foros auspiciados por la UNESCO la necesidad de que

...los programas de formación se definan en términos de perfiles de competencia que hay que dominar y no en términos de conocimientos que hay que transmitir y devolver; [por el contrario], los objetivos prioritarios de los currículos deberían formularse en términos de capacidades de análisis de situaciones complejas, capacidades de emprender, capacidades de reaccionar como ciudadano responsable para desarrollar una cultura de paz. (UNESCO, Conferencia Mundial sobre la Educación Superior, 1998, p. 21)

En respuesta a estas nuevas demandas educativas se ensayan y propician nuevos enfoques pedagógicos cimentados en teorías psicológicas de base epistemológica constructivista como los paradigmas cognitivo, psicogenético y sociocultural, centrados en la persona y en la construcción propia y social del conocimiento.

En relación con la pertinencia hay consenso en el nivel mundial de la importancia de ensayar sistemas educativos flexibles, ajustados a las necesidades de las personas. La educación debe proponerse como tarea permanente estar en contacto con la cultura local, regional y global, a fin de brindar pertinencia, eficacia y eficiencia educativas. Esto implica una diversificación de los métodos de enseñanza, particularmente en la educación superior, con el propósito de abrir nuevas oportunidades formativas para que toda la población se beneficie con el incremento de competencias de alto nivel, ajustadas a las necesidades profesionales, personales y laborales de nuestro tiempo.

La cultura general y la formación crítica y reflexiva favorecen una ciudadanía responsable, consciente de sí misma y de su realidad, por lo que ofrece mayores posibilidades para la toma de decisiones adecuadas respecto de la propia vida, las relaciones y el futuro. Por esta razón, la educación debe ser de calidad; es decir, debe permitir no sólo el desempeño laboral, sino también desarrollar capacidades para articular una biografía coherente con las aspiraciones personales, y favorecer la convivencia en armonía en concordancia con una conducta personal y socialmente responsable.

Superar la visión tecnocrática de la pedagogía que imperó a lo largo del siglo $\mathrm{XX}$ parece ser el principal reto de la educación en la era de la modernidad reflexiva. En la Conferencia de las Américas sobre Educación para todos, realizada en Santo Domingo, República Dominicana, en febrero de 2000, se contabilizó como uno de los principales logros en educación en la década de 1990, la inclusión progresiva de temas de educación para la vida en las modalidades formal y no formal (UNESCO, Marco de Acción de Dakar, 2000). Entre los temas pendientes y como parte de los desafíos para este siglo, están “... asegurar que las escuelas favorezcan la vida saludable, el ejercicio de la ciudadanía y los aprendizajes básicos para la vida" (UNESCO, Marco de Acción de Dakar, 2000, p. 37). Al respecto, en el capítulo titulado Educación para la vida, se propone que:

1. La educación debe proporcionar habilidades y competencias para vivir y desarrollar una cultura del derecho, el ejercicio de la ciudadanía y la vida democrática, la paz y la no 
discriminación; la formación de valores cívicos y éticos; la sexualidad; la prevención de la drogadicción y el alcoholismo; la preservación y cuidado del medio ambiente.

2. La inclusión de estos aprendizajes como contenidos curriculares, transversales y/o disciplinares, constituye un desafío asociado a la nueva construcción curricular, al trabajo conjunto con la comunidad y al rol del profesor como modelo de las competencias para la vida. (UNESCO, Marco de Acción de Dakar, 2000, p. 39)

El concepto de educación para la vida busca atender diversos problemas originados en la fase de transición de la sociedad occidental del capitalismo industrial al postindustrial. Refleja la toma de conciencia a escala planetaria de que la educación juega un papel crucial en el proceso de producción y reproducción del sistema social. La educación debe contribuir para que nuestra sociedad acceda a formas de organización general y a una estructuración de la personalidad más coherentes con un modelo democrático en el que se propicie la equidad en todas su formas: de género, económica, política, jurídica, cultural y social.

\section{Reflexiones finales}

Los lemas de la UNESCO “aprender a aprender", "aprender a ser", "aprender a hacer", "aprender a vivir juntos", muestran el salto cualitativo que debe dar la educación para ponerse a la altura de los tiempos. La nueva economía apoyada en la tecnología, el conocimiento y la organización política democrática exigen una ciudadanía capaz de comprender su realidad y su contexto, y de tomar decisiones orientadas a la preservación de la propia vida, de la de los otros y del medio ambiente. La responsabilidad sólo es practicable cuando se es consciente, al menos en lo que es posible, de las consecuencias de los propios actos. Las personas que vivimos hoy debemos ser cada vez más responsables de nosotras mismas y, consecuentemente, en nuestras relaciones.
Gracias a los avances de la psicología cognitiva, psicogenética y la sociocultural, sabemos que entre más educación recibe una persona, mayores son sus oportunidades de acceder al trabajo, de reflexionar y de cobrar conciencia de su vida y su entorno (Piaget, 2001; Vigotski, 2001). Entre más conscientes somos, mayor responsabilidad podemos asumir respecto de las consecuencias de nuestras acciones y de las decisiones que tomamos. Ese es el desafío de la educación contemporánea: ofrecer a las personas de todas las edades y condiciones una formación que, además de favorecer la adquisición de conocimientos relevantes, y el desarrollo de habilidades $\mathrm{y}$ aptitudes sociales y comunicativas, de acceso a una consistente cultura general que permita entender el entorno y el conocimiento personal.

Las necesidades educativas del presente indican que la educación debe propiciar y facilitar la adquisición de nuevas competencias cognitivas, personales y sociales, indispensables para vivir y desarrollarse en los niveles social, personal y laboral. Entre ellas se señalan las siguientes:

- Competencias cognitivas: solución de problemas, pensamiento crítico, formulación de preguntas pertinentes, búsqueda de la información relevante, realización de juicios informados, uso eficiente de la información, realización de observaciones, investigaciones, invención y creación, análisis de datos o presentación de trabajos y conclusiones de forma eficiente, tanto oralmente como por escrito.

- Competencias metacognitivas que capaciten a la persona para la autorreflexión y la autoevaluación.

- Competencias sociales que permitan participar y, en su caso, dirigir discusiones de grupo, persuadir, trabajar cooperativamente, etc.

- Disposiciones afectivas que hagan posible un trabajo eficaz, tales como la perseverancia, la motivación intrínseca, un buen nivel de iniciativa y una actitud responsable, así como la percepción de autoeficacia, o la suficiente independencia, flexibilidad y capacidad para enfrentarse a situaciones frustrantes cuando resulte necesario. (Vizcarro \& León, 1998, pp. 17-18) 
Las últimas conferencias mundiales sobre educación han dado los primeros pasos hacia la reforma educativa histórica que marcará el cambio de época hacia el cual nos dirigimos de manera inexorable. Esto supondrá tiempo, ya que envuelve una transformación radical en los niveles filosófico, teórico y metodológico de la educación. Lo que es un hecho es que se ha tomado conciencia a escala mundial de la necesidad del cambio educativo y de la relevancia de esta institución social en el rumbo que tome en el futuro la humanidad.

Nadie pone en duda en la actualidad que es preciso ofrecer una educación para la democracia, orientada a la preservación de la vida en el planeta, la felicidad, el desarrollo personal y social, la paz y la convivencia. Esto presume una formación que rompa con las diferencias tradicionales entre géneros, más coherente con las características y necesidades de los individuos y la sociedad de nuestro tiempo. Estos elementos permitirán a las personas enfrentar con más recursos intelectuales y afectivos el cambio y la diferencia. Como apuntan los autores estudiados, la educación como institución del futuro deberá atender las necesidades sociales de la modernidad reflexiva de hoy: la sociedad del riesgo, la individualización como forma social y, la reflexión y la reflexividad. El primer paso es identificar y esclarecer sus manifestaciones en el ámbito educativo y ello exige investigación interdisciplinaria, en particular en el campo de la sociología de la educación.

El hecho de que existan marcos explicativos de la magnitud de la teoría de los Sistemas Sociales y de la Modernidad Reflexiva, abre nuevas posibilidades para superar el déficit teórico y tecnológico que prevalece en la teoría de la educación y en la pedagogía. Las funciones tradicionales de la educación se han superado por otras más complejas y diversas, y quizá esta etapa de confusión sea la oportunidad para reemplazar la base normativa y arbitraria de la pedagogía tradicional por una base científica. Pasar del "deber ser" al "conocer" en el campo de las ciencias de la educación es indispensable en nuestro tiempo, máxime si se considera que:

...para una organización sin tecnología apenas es posible controlar los procesos de decisión que se desarrollan de facto sentando premisas de decisión (lo que al mismo tiempo contribuye a explicar el aspecto arbitrario, sobre el que a menudo se llama la atención, de los requisitos burocráticos). (Luhmann, 1996, p. 69)

\section{Notas}

1. Entropía negativa.

\section{Referencias bibliográficas}

Beck, U., \& Beck-Gernsheim, E. (2001). El normal caos del amor. Las nuevas formas de la relación amorosa. Barcelona: Paidós.

Beck, U., Giddens, A., \& Lash, S. (2001). Modernización reflexiva. Política, tradición y estética en el orden social moderno. Madrid: Alianza Universidad.

Giddens, A. (1998). La transformación de la intimidad. Sexualidad, amor y erotismo en las sociedades modernas. Madrid: Cátedra.

Hargreaves, A. (2003). Profesorado, cultura y posmodernidad: Cambian los tiempos, cambia el profesorado. Madrid: Ediciones Morata.

Luhmann, N. (1996). Teoría de la sociedad y pedagogía. Barcelona: Paidós.

Luhmann, N. (1998). Sistemas sociales. Lineamientos para una teoría general. Barcelona: Anthropos.

Luhmann, N. (2000). La realidad de los medios de masas. Barcelona: Anthropos.

Marx, K. (1974). Manuscritos de Economía y Filosofía. Madrid: Alianza Editorial. 
Marx, K. (1980). El capital. México: Siglo XXI.

Piaget, J. (2001). Inteligencia y afectividad. Argentina: Aique.

Vigotski, L. S. (2001). Psicología pedagógica. Argentina: Aique.

Vizcarro, C. \& León, J. (1998). Nuevas tecnologías para el Aprendizaje. Madrid: Pirámide.

UNESCO. (1998). Conferencia Mundial sobre la Educación Superior. La
Educación Superior en el siglo XXI: Visión y acción. París: Organización de las Naciones Unidas para la Educación, la Ciencia y la Cultura.

UNESCO. (2000). Foro Mundial sobre la Educación. Informe Final. Francia: Organización de las Naciones Unidas para la Educación, la Ciencia y la Cultura.

UNESCO. (2000). Foro Mundial sobre la Educación. Marco de Acción de Dakar. Francia: Organización de las Naciones Unidas para la Educación, la Ciencia y la Cultura. 